\title{
A CONCEPÇÃO DE DISPOSITIVOS PEDAGÓGICOS QUE INTEGRAM AS TIC*
}

Joana Peixoto**

\section{RESUMO}

O presente artigo é baseado na pesquisa "Apoio e avaliação pedagógica de um dispositivo de formação não presencial: a utilização das tecnologias em ambientes virtuais como uma possibilidade de inovação pedagógica". Tal pesquisa foi realizada entre 2007 e 2008, junto aos professores que utilizam o ambiente virtual de aprendizagem Moodle em disciplinas semipresenciais nos cursos de graduação da Universidade Católica de Goiás. Partindo do pressuposto de que as formas de utilização das TIC podem ser reveladoras das práticas pedagógicas, possibilitando ações inovadoras, realizou-se uma pesquisa-ação que teve como objetivo final a proposição de um "Roteiro de apoio e avaliação de dispositivos de formação mediados por ambientes virtuais de aprendizagem".

Palavras-chave: Abordagem sócio-técnica. Ambiente virtual de aprendizagem. Dispositivo pedagógico. Inovação pedagógica.

\section{INTRODUÇÃO}

A Universidade Católica de Goiás (UCG), com o Programa de Graduação Itinerante, atua na área da educação a distância (EAD) desde 1998. A partir de 2003, o Centro de Educação Aberta e a Distância (CEAD) passou a oferecer cursos com a utilização da mídia digital. Atualmente, oferece formação em diversas categorias: Educação Continuada, Extensão, Pós-graduação, Programa de apoio ao aluno, Grupo de estudo. Além disso, algumas disciplinas de diversos cursos de graduação são oferecidas com a "metodologia semipresencial, buscando implementar

\footnotetext{
* Artigo recebido em 28/11/2008 e aprovado em 23/04/2009.

** Professora do Programa de Pós-graduação em Educação da Universidade Católica de Goiás. Doutora em Ciências da Educação, especialista em Informática e Educação. E-mail: joanagyn@ yahoo.com.br
} 
metodologias e estratégias no sentido de uma flexibilização para o aluno do tempo e espaço, como também, o desenvolvimento de uma cultura institucional no uso da tecnologia no processo ensino-aprendizagem". (Carvalho e Martelli, 2005, p. 3).

A pesquisa na qual se baseia este artigo tomou como campo empírico as disciplinas ministradas na forma semipresencial no ano de 2008 na UCG, visando acompanhar as práticas dos professores por elas responsáveis, para observar como ou até que ponto a utilização das tecnologias pode revelar o desenvolvimento de práticas pedagógicas inovadoras.

Trata-se de uma pesquisa-ação, que teve como objetivo final desenvolver uma Proposta de apoio e avaliação de dispositivos ${ }^{1}$ de formação mediados por AVA (ambientes virtuais de aprendizagem).

\section{EDUCAÇÃO A DISTÂNCIA, AMBIENTES VIRTUAIS DE APRENDIZAGEM E PARADIGMA EDUCACIONAL}

O discurso pedagógico brasileiro contemporâneo sobre o uso das tecnologias na educação segue as orientações adotadas pelos estudos referentes aos processos pedagógicos em geral. Dessa forma, os estudos acerca das teorias da educação e dos processos pedagógicos com a utilização das tecnologias seguem as tendências pedagógicas clássicas como o construtivismo (Vygotsky), o desenvolvimento por fases (Piaget) ou a educação popular (Paulo Freire) (AraúJo, 2008, Реixoto, 2007).

Esse discurso apresenta dois fortes pontos de convergência: 1) a vinculação da apropriação das TIC (tecnologias de informação e de comunicação) pela educação ao processo de transformações sociais que levam à configuração da sociedade em rede e 2) a fundamentação em um discurso do tipo construtivista.

Embora possuam tais pontos de convergência e sigam as orientações das tendências pedagógicas em geral, as explicações sobre as formas de relação entre as TIC e a educação possuem especificidades. Observa-se um movimento que oscila entre a visão da tecnologia como ferramenta ou meio flexível e adaptável ao uso, imputado pelo homem (visão instrumental), e a atribuição à tecnologia do poder de configurar a cultura e a sociedade (determinismo tecnológico). Estas duas abordagens revelam, em parte, a dinâmica da visão contemporânea sobre a tecnologia. Tal dinâmica se reflete na apropriação da tecnologia pelo 
discurso e, consequentemente, pelas práticas pedagógicas (ARAÚJo, 2008; Peiхото, 2008).

Essa análise pode também ser aplicada aos estudos referentes à educação a distância ou à utilização dos ambientes virtuais de aprendizagem em cursos que adotam a metodologia a distância ou semi-presencial².

No que diz respeito à EAD, a abordagem determinista revela-se, sobretudo, nos estudos ou teóricos que apresentam a EAD como nova "modalidade de ensino" (Peters, 2001; 2004). Segundo essa abordagem, a EAD opõe-se à educação presencial, que se revela obsoleta e conservadora. Assim, a EAD é tida como uma modalidade ou um paradigma educacional adequado aos novos tempos. Os meios tecnológicos que permitem a instalação dessa "modalidade de ensino" são dotados do poder de instaurar um novo paradigma pedagógico, aquele baseado na: a) mediação pedagógica por meio da mediação tecnológica, b) autonomia do aluno, c) interatividade d) colaboração. Nesse caso, cabe ao professor adaptar-se ao novo meio tecnológico e desenvolver as competências demandadas por este para realizar, de forma quase automática, a educação segundo os moldes demandados pela sociedade da informação.

Pode-se, ainda, considerar os ambientes virtuais de aprendizagem como meros instrumentos técnicos neutros. Esses são vistos como ferramentas cujo alcance depende da forma como são utilizados pelo professor (Moran, 2003, 2007, 2008; Valente e Almeida, 2007; Valente; Prado; AlmEIDA, 2003). Se apropriados segundo um método transmissivo, serão disseminadores de uma pedagogia transmissiva, baseada na reprodução de conteúdos. Se apropriados numa dinâmica colaborativa e interativa, implantarão uma educação em rede, conectada com as demandas da sociedade tecnológica.

Tanto nessa última visão, instrumental, como na não-instrumental, o professor é responsabilizado pelo sucesso do projeto pedagógico adotado. Daí a insistência na preparação do mesmo, segundo as competências em questão. Pode-se verificar nessas visões uma pouca abrangência dos fatores macro-estruturais. Isso se revela numa certa ingenuidade quanto aos vínculos entre demandas econômicas e sociais excludentes e os projetos educacionais que utilizam as TIC. Por exemplo, o aprendizado ao longo da vida, a preparação para o trabalho coletivo ou a importância da autonomia são tomados como referências para a ação com os alunos, sem que se destaque o fato que essas metas significam uma preparação para o nosso tempo porque atendem a demandas do mercado de trabalho 
neoliberal. Ou seja, a educação de qualidade por meio da inclusão digital não atende apenas a desejos dos alunos que freqüentam as escolas: ela coaduna-se a um projeto econômico que não visa a emancipação dos trabalhadores e nem a formação da cidadania, conforme o propalado, mas a ampliação de um mercado de consumidores e de um quadro de trabalhadores competentes segundo as leis do mercado (BARRETO, 2003; Barreto et al, 2006; Barreto e Leher, 2008; Belloni, 2001, 2002; Pretto, 1999, 2001, 2007; Pretto e Pinto, 2006).

\section{Os DISPOSITIVOS DE FORMAÇÃO A DISTÂNCIA E A INOVAÇÃO}

Se a visão instrumentalista faz do objeto técnico "um objeto flexível, formatável de qualquer maneira e não leva em conta a rigidez, especialmente física, das tecnologias" (VedeL, in VitALIs, 1994, p.27), supervalorizando o poder do sujeito que o manipula, a visão determinista oculta a dimensão humana do objeto técnico que é considerado como entidade autônoma (SimONDON, 1989).

Considerando que as diferentes abordagens desenvolvidas acima têm seus limites, Vitalis (1994) propõe outra via, a sociopolítica dos usos, que tenta articular, num mesmo quadro analítico, as contribuições das abordagens precedentes e considera que a

utilização das tecnologias numa sociedade se situa no cruzamento entre quatro do, lógicas [...] de um lado, uma lógica técnica e uma lógica social que é possível de articular ao se recorrer ao conceito de configuração sóciotécnica. Por outro lauma lógica de oferta e uma lógica de uso cuja interação complexa pode principalmente - mas não exclusivamente - ser atingida por uma análise em termos de representação. (VEDEL, 1994, p.29).

O cruzamento dessas quatro lógicas permitiria a especificação das relações de uso de cada tecnologia, relações que definem não só uma relação com o objeto técnico, mas também uma relação social entre os sujeitos.

$\mathrm{Na}$ abordagem sociopolítica dos usos, o usuário ocupa um lugar privilegiado, sendo "considerado como sujeito ativo de suas relações - de uso - com as mídias ou tecnologias de informação e comunicação, e o objetivo do pesquisador é investigar as formas destas relações, os procedimentos e modalidades de apropriação" (BELLONI, 2001, p.63). 
Dita ainda de outra forma, a noção da representação dos usuários se articula em três níveis: o da técnica, o do cotidiano e o dos objetos (Proulx, 1994). Assim, a técnica pode ser considerada como os outros modos culturais, ou seja, modos que mediatizam a relação do homem com o mundo, do qual a tecnologia faz parte.

As tecnologias são vistas, então, como inseparáveis das formas de socialização e de cultura que as acompanham (SANTAELla apud SANTOS, 2005) ou que lhes impõem obstáculos, por meio de todo um fluxo e feixes de relações recíprocas entre seres humanos e objetos técnicos (op. cit.). Essa rede dinâmica pode ser chamada de cenário sociotécnico, que inclui uma infra-estrutura tecnológica e também sociabilidades que se articulam de forma "recursiva e implicada" (id., p.200).

$\mathrm{Na}$ verdade, o que se propõe aqui é encarar as tecnologias sobretudo como objeto de estudo e não apenas como recursos didático-pedagógicos (Oliveira, 2001). Ou seja, em vez de colocar o foco nas prioridades didáticas das tecnologias, enfatizar a maneira como os sujeitos delas se apropriam. A interatividade e a colaboração, por exemplo, não se instalam no processo educativo apenas porque se decidiu mediatizar a aprendizagem pelas tecnologias. Em outras palavras, essas características didático-pedagógicas não se instalam por si próprias. É preciso prever a utilização dos dispositivos tecnológicos com a finalidade de responder a um determinado aspecto de um determinado tipo de aprendizagem. $\mathrm{Ou}$ seja, mesmo que as tecnologias ofereçam cada vez mais possibilidades de responder às múltiplas exigências particulares dos programas de formação, as soluções técnicas em si não respondem a tais exigências. Não se trata de priorizar as soluções tecnológicas, mas suas formas de apropriação (MARCHAND e LoISIER, 2005, p. XII-XIV).

A QUESTÃO DA PESQUISA: OS DISPOSITIVOS DE FORMAÇÃO A DISTÂNCIA E A INOVAÇÃO

Ensinar a distância é ensinar com a mediação de suportes comunicacionais, uma vez que os conteúdos de ensino, os exercícios, etc devem ser transmitidos ao aprendiz por intermédio de meios de informação e de comunicação: documentos escritos e suportes audiovisuais clássicos ou digitais. Essa é uma das explicações para a importância fundamental atribuída, nos programas de $\mathrm{EAD}$, tanto aos meios utilizados como à concepção do material didático. 
Além disso, a ruptura entre o ensino e a aprendizagem, o isolamento do aprendiz e a concepção modular das unidades de ensino exigem que os profissionais envolvidos nos programas de EAD se dediquem a uma explicitação exaustiva do processo pedagógico: definição de objetivos, seleção, estruturação e acessibilidade de conteúdos, apoio à aprendizagem, mediação dos conteúdos, escolha das mídias e criação de um ambiente de aprendizagem. Observa-se que, na educação presencial, esses procedimentos foram banalizados, sendo raramente questionados ou assumidos como responsabilidade coletiva de quem concebe e executa os programas educacionais.

É por isso que a utilização das TIC em projetos de EAD pode significar uma ocasião de mudanças na prática pedagógica do professor. A introdução das TIC pode ser a ocasião de um questionamento dos hábitos de trabalho, considerando-se a revisão das finalidades pedagógicas e da maneira de mobilizar os meios para atingi-las. Alguns autores consideram que a presença das TIC como meio educacional pode favorecer, através da reflexão sobre a formação, a identificação tanto dos fatores que geram inovações quanto das condições de estabelecimento de novas práticas (Berrouk e Jaillet, 2005; Bonneton, 1999; Charlier e Peraya, 2000).

No entanto, para além das transformações relacionadas à utilização adequada das mídias, estão as mudanças introduzidas no dispositivo de formação, que induzirão uma mudança na prática pedagógica. Portanto, quando se decide utilizar métodos e técnicas de ensino a distância, mudanças importantes são introduzidas: mais atividades de trabalho em grupo, o uso de recursos externos ou a pesquisa como fonte de exercícios, dentre outras. Essas mudanças no dispositivo de formação que integram as TIC podem ser radicais, além de imporem sobrecarga de trabalho e de responsabilidades ao professor. Assim, se um professor passa a trabalhar num contexto de EAD, isso requer outro horário de trabalho, disponibilidade para o acompanhamento virtual, outro tipo de contato com os alunos e, especialmente, outra representação de sua ação e do que ela pode trazer aos mesmos. Dessa forma, a apropriação pedagógica das TIC pode conduzir o professor a um questionamento metodológico essencial, ou seja, pode levar à problematização de representações cristalizadas e práticas triviais, banalizadas pelo uso repetido e com base em fundamentos pouco esclarecidos.

Esta pesquisa buscou, então, compreender como as formas de utilização das TIC podem ser reveladoras das práticas pedagógicas e, 
sobretudo, ser um fermento da colaboração entre pares e da participação do professor na concepção, na gestão e na regulação dos dispositivos de formação, de modo a possibilitar práticas inovadoras ${ }^{3}$.

Pretendeu-se questionar a forma e a estrutura dos dispositivos de formação colocados em prática no CEAD/UCG, já que o objeto de estudo proposto são as experiências de oferta de disciplinas dos cursos de graduação na modalidade semi-presencial que utilizam a plataforma Moodle.

\section{A PESQUISA}

Conforme foi prenunciado, a pesquisa em referência foi realizada no contexto dos cursos de graduação da UCG. No ano letivo de 2008, quarenta e três disciplinas de sete cursos diferentes realizaram a experiência de utilização do AVA. Dessas, trinta adotaram a metodologia semipresencial e treze utilizaram o AVA como apoio aos momentos presenciais.

Os sujeitos desta pesquisa são os professores dos cursos de graduação da UCG que utilizam o AVA em cursos semipresenciais. Cerca de 30 professores se enquadraram neste requisito no ano letivo de 2008 . Foi tomada uma amostra de 14 professores, que foram alvo de observação, acompanhamento ou entrevistas.

Os dados foram coletados de forma diversificada em cada etapa da pesquisa, incluindo a realização de entrevistas semi-estruturadas com oito professores da disciplina "Educação, comunicação e mídia" no primeiro semestre e com seis professores de diversas disciplinas que utilizam o AVA, no segundo semestre.

Os dados provenientes da presente investigação e de outras pesquisas (sobre a utilização de recursos midiáticos como ajuda para a aprendizagem e para o ensino) indicam a necessidade de se colocar em questão o alcance pedagógico das TIC e dos AVA. Na verdade, diversos dispositivos de EAD são construídos sem serem testados, ou, quando o são, sofrem os efeitos de uma representação mistificada dos mesmos. Assim, se as TIC, os AVA e os dispositivos de EAD podem ser avaliados quanto ao seu potencial didático-pedagógico, os resultados empíricos da aplicação destes recursos precisam ser objeto de análise.

Ou seja, predomina um discurso indicando que se aprende e se ensina de forma diferente com as TIC, sem que os elementos dessa dife- 
rença sejam realmente explicitados ou atualizados, em função de cada novo recurso tecnológico utilizado, como é o caso dos AVA em cursos do tipo presencial e semipresencial. Enfim, o debate desloca-se para os novos objetos técnicos, mas as questões fundamentais que cada um destes objetos coloca não foram suficientemente analisadas, devendo ser testadas empiricamente e aprofundadas teoricamente.

A partir dessas considerações, propõe-se um Roteiro para o apoio e a avaliação de dispositivos de formação mediados por ambientes virtuais de aprendizagem, indicando que seus criadores e seus atores precisam de meios para avaliar a eficácia, o alcance e os efeitos destes dispositivos sobre os diferentes aspectos do ensino e da aprendizagem: expectativa dos atores, qualidade pedagógica e didática dos programas, design pedagógico, dentre outros.

\section{Projeto de InTEGRação do AVA}

A integração do AVA à prática docente insere-se, necessariamente, num processo de formação continuada dos professores, que inclui o desenvolvimento de competências relativas à concepção de dispositivos AVA, sua testagem e avaliação.

Considerando o professor como profissional autônomo e as tecnologias na perspectiva sociotécnica, não caberia nesse processo uma imposição de normas ou prescrições a serem seguidas. Nesse caso, indica-se a formação de equipes de professores voluntários em cada departamento, segundo referencial de competências definidas. Assim que houver mais de dois professores por departamento utilizando o AVA, pode ser proposto o desenvolvimento de um projeto para sua integração à prática docente. Assim, em cada departamento, uma equipe de professores voluntários desenvolverá competências associadas ao uso deste recurso.

\section{CONCEPÇÃO DO DISPOSITIVO}

O exercício de análise do processo de concepção de dispositivos em AVA visou desenvolver uma ferramenta conceitual para guiar os professores nesse processo. $\mathrm{O}$ objetivo foi compreender e analisar os problemas encontrados pelos professores na implementação de seu projeto e de conceber uma ferramenta de trabalho para abordar as questões a tratar e operar a partir das escolhas pedagógicas para a concepção de dispositivos. 
A ferramenta que se propõe aqui se baseou em modelos existentes (KensKi, 2005-2006; Villiot-LeclercQ, 2007) e nos dados obtidos por meio das entrevistas e observações: a forma como os professores concebem suas atividades recorrendo aos AVA, a partir das questões que eles se colocam e da observação da gestão de suas práticas.

O Roteiro indica 12 dimensões de um dispositivo. Cada uma das dimensões engloba um aspecto em particular do desenvolvimento de um dispositivo pedagógico. Estes aspectos são complementares, apresentando-se sob a forma de um continuum sobre o qual o professor é convidado a posicionar a atividade pedagógica que ele quer implementar, questionando suas intenções, os objetivos de sua disciplina assim como o contexto no qual esta se coloca. Para um dispositivo dado, certas dimensões podem ter mais importância que outras ou influenciá-las mais. O espaço no qual se colocará o dispositivo orientará bastante as respostas às questões que o professor se coloca em cada dimensão. Concretamente, essa ferramenta deverá ser utilizada como uma lista de questões a se propor, seja ao professor ou ao designer, assim que se deseja implementar um dispositivo integrando as TIC. Cada um aprofundará sua reflexão em função de seus objetivos ou de seu contexto. Não se trata nunca de tomar partido por um ou por outro pólo das dimensões, mas de posicionar-se num continuum, de refletir sobre as razões dessa escolha e de traduzi-las em seu dispositivo.

A figura 1, à página seguinte, apresenta as doze dimensões propostas assim como os continua sobre os quais o professor pode se posicionar e efetuar uma escolha para seu dispositivo. Elas estão organizadas em quatro categorias:

1. orientações e escolhas pedagógicas iniciais;

2. atores e papéis;

3. atividades;

4. ferramentas e processos.

A partir daí, formulou-se cada dimensão na forma de questões, indicando o efeito das respostas sobre a concepção e a implementação do dispositivo. As questões fazem referência às duas extremidades do continuum: para cada uma existe uma infinidade de nuances. Além disto, as respostas estão ligadas ao tipo de conteúdo abordado, às características cognitivas e culturais do grupo de alunos e a diversos outros aspectos 
inerentes a cada contexto (institucionais, políticas, estruturais, etc.) no qual o dispositivo será implementado.

Figura 1- As doze dimensões para conceber um dispositivo pedagógico

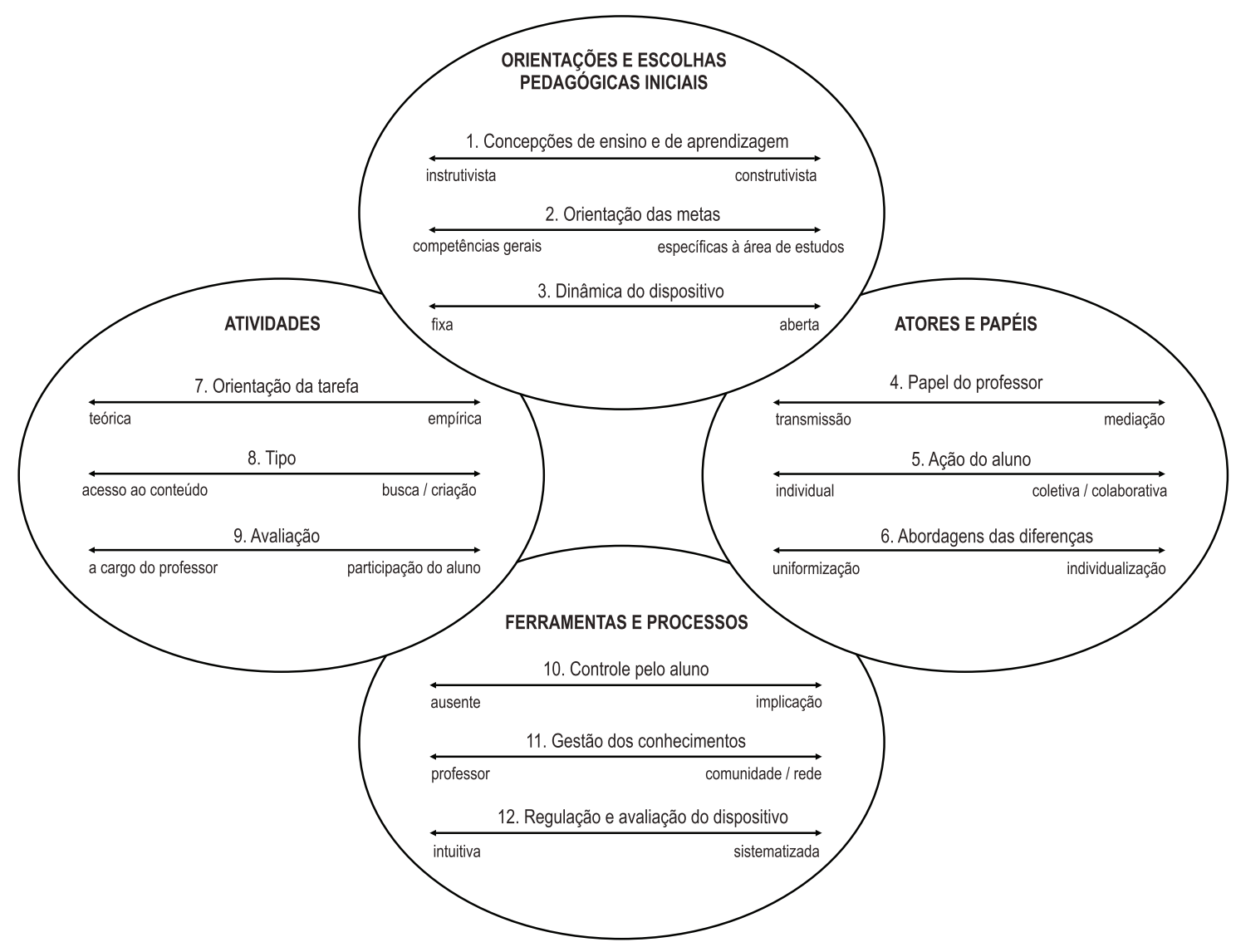

Em seguida à série de questionamentos propostos, o trabalho de redação e de implementação do dispositivo começa, baseado no conhecimento em profundidade dos conteúdos e na imaginação do professor. 
Quadro 1 - As 12 dimensões de questionamentos que conduzem às escolhas pedagógicas.

\begin{tabular}{|c|c|c|}
\hline & Dimensões e questões a serem colocadas & Efeito sobre o dispositivo \\
\hline \multirow{9}{*}{ 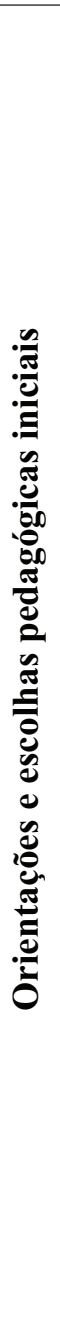 } & \multicolumn{2}{|c|}{$\begin{array}{l}\text { 1. Concepção de ensino e de aprendizagem: Qual visão do ensino e da aprendizagem } \\
\text { prevalece? }\end{array}$} \\
\hline & $\begin{array}{l}\text { Aprender quer dizer receber conhecimentos? } \\
\text { Ensinar quer dizer transmitir conhecimentos? }\end{array}$ & $\begin{array}{l}\text { O dispositivo será bem explícito em } \\
\text { relação às funções do professor e o } \\
\text { ambiente será concebido priorizando } \\
\text { as formas e condições de acesso às } \\
\text { informações, materiais e recursos. }\end{array}$ \\
\hline & $\begin{array}{l}\text { Aprender quer dizer construir aprendizagens? } \\
\text { Ensinar significa conduzir o processo de } \\
\text { aprendizagem? }\end{array}$ & $\begin{array}{l}\text { O dispositivo será bem explícito quanto } \\
\text { às funções do aluno e o ambiente será } \\
\text { concebido de forma a facilitar a busca } \\
\text { de informações em múltiplas fontes e a } \\
\text { manipulação de objetos, a simulação, por } \\
\text { exemplo. }\end{array}$ \\
\hline & \multicolumn{2}{|c|}{ 2. Orientação das metas/objetivos: Como o objetivo da formação pode ser situado? } \\
\hline & $\begin{array}{l}\text { Os objetivos são independentes ou centrados } \\
\text { em um aspecto em particular? }\end{array}$ & $\begin{array}{l}\text { As atividades serão centradas em torno de } \\
\text { objetivos bem precisos. }\end{array}$ \\
\hline & $\begin{array}{l}\text { Os conhecimentos desenvolvidos na disciplina } \\
\text { devem estar conectados a uma área de estudo } \\
\text { mais ampla? }\end{array}$ & $\begin{array}{l}\text { O dispositivo situará a disciplina numa } \\
\text { área de conhecimento e as atividades farão } \\
\text { referência a ela. }\end{array}$ \\
\hline & \multicolumn{2}{|c|}{$\begin{array}{l}\text { 3. Dinâmica do dispositivo: Como será organizado o espaço, o tempo e o controle do } \\
\text { dispositivo? }\end{array}$} \\
\hline & $\begin{array}{l}\text { Os alunos devem assistir todos juntos no } \\
\text { mesmo lugar e/ou ao mesmo tempo às } \\
\text { atividades? }\end{array}$ & $\begin{array}{l}\text { O dispositivo deverá prever ferramentas } \\
\text { de trabalho síncrônicas e/ou um ambiente } \\
\text { físico comum para a aprendizagem. }\end{array}$ \\
\hline & $\begin{array}{l}\text { É possível seguir a formação a distância } \\
\text { em diferentes momentos e/ou segundo um } \\
\text { processo pessoal? }\end{array}$ & $\begin{array}{l}\text { O dispositivo preverá ferramentas de } \\
\text { trabalho assíncrônicas e/ou o ambiente } \\
\text { virtual apresentará uma possibilidade de } \\
\text { adaptação. }\end{array}$ \\
\hline \multirow{7}{*}{ 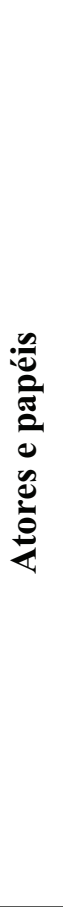 } & \multicolumn{2}{|c|}{ 4. Papel do professor: Qual será o meu lugar na formação? } \\
\hline & $\begin{array}{l}\text { Meu principal papel é fornecer informações } \\
\text { sobre os conteúdos? }\end{array}$ & $\begin{array}{l}\text { O dispositivo será organizado em torno da } \\
\text { aquisição de conhecimentos precisos pelos } \\
\text { alunos. }\end{array}$ \\
\hline & $\begin{array}{l}\text { Meu papel principal é acompanhar os alunos } \\
\text { em seu processo de aprendizagem? }\end{array}$ & $\begin{array}{l}\text { O dispositivo colocará o professor ao lado } \\
\text { dos alunos e lhes propiciará certo nível de } \\
\text { controle. A tutoria poderá tomar forma de } \\
\text { expertise ou ajuda técnica. }\end{array}$ \\
\hline & \multicolumn{2}{|c|}{ 5. Ação do aluno: Qual será o lugar do aluno na formação? } \\
\hline & $\begin{array}{l}\text { É importante permitir aos alunos entrar em } \\
\text { contato com os outros membros do grupo de } \\
\text { aprendizagens? }\end{array}$ & $\begin{array}{l}\text { O dispositivo deverá prever momentos } \\
\text { de troca e de participação com a rede de } \\
\text { alunos. }\end{array}$ \\
\hline & \multicolumn{2}{|c|}{ 6. Abordagem das diferenças individuais/ culturais } \\
\hline & $\begin{array}{l}\text { É importante levar em conta as diferenças } \\
\text { individuais dos alunos. estilos cognitivos, } \\
\text { fatores afetivos, conhecimentos anteriores, } \\
\text { idade, situação de trabalho, dentre outros? }\end{array}$ & $\begin{array}{l}\text { O dispositivo pode diferenciar as atividades } \\
\text { dos alunos em função de sua situação } \\
\text { pessoal e propor encaminhamentos } \\
\text { alternativos variáveis (fazer referência a } \\
\text { situações vividas, adaptar horários, dentre } \\
\text { outros). }\end{array}$ \\
\hline
\end{tabular}




\begin{tabular}{|c|c|c|}
\hline & Dimensões e questões a serem colocadas & Efeito sobre o dispositivo \\
\hline 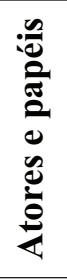 & $\begin{array}{l}\text { Os alunos se originam de meios culturais } \\
\text { diferentes? Esta dimensão é importante } \\
\text { em relação às atividades propostas para os } \\
\text { alunos? }\end{array}$ & $\begin{array}{l}\text { Este aspecto se traduz por adaptações de } \\
\text { horários ou da apresentação da informação, } \\
\text { das atividades de aprendizagem por } \\
\text { problema, fazendo referência a situações } \\
\text { vividas, experiências anteriores, dentre } \\
\text { outras. }\end{array}$ \\
\hline \multirow{9}{*}{ 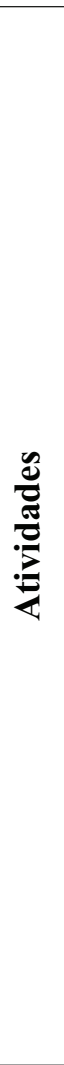 } & \multicolumn{2}{|c|}{ 7. Orientação da tarefa: A que tipo de tarefa os alunos serão confrontados? } \\
\hline & $\begin{array}{l}\text { As tarefas são acadêmicas, ligadas a pontos } \\
\text { precisos de uma determinada teoria? }\end{array}$ & $\begin{array}{l}\text { Exercícios de compreensão ou de aplicação } \\
\text { e pesquisas bibliográficas podem ser } \\
\text { apropriados. }\end{array}$ \\
\hline & $\begin{array}{l}\text { As tarefas demandam o domínio de } \\
\text { competências ligadas a diversas áreas ou } \\
\text { vinculadas a uma prática particular? }\end{array}$ & $\begin{array}{l}\text { As atividades de aprendizagem serão } \\
\text { próximas da realidade do campo e do } \\
\text { contexto de execução. }\end{array}$ \\
\hline & \multicolumn{2}{|c|}{ 8. Tipo: Que tipo de atividade será proposta aos alunos? } \\
\hline & $\begin{array}{l}\text { Os alunos deverão consultar uma grande } \\
\text { quantidade de informações? }\end{array}$ & $\begin{array}{l}\text { O ambiente deverá permitir o acesso e a } \\
\text { navegação facilitada entre os conteúdos e } \\
\text { materiais do curso. }\end{array}$ \\
\hline & $\begin{array}{l}\text { Os alunos deverão eles mesmos elaborar e } \\
\text { organizar certos conteúdos? }\end{array}$ & $\begin{array}{l}\text { O dispositivo deverá prever modalidades } \\
\text { de elaboração de conhecimentos com as } \\
\text { ferramentas apropriadas. }\end{array}$ \\
\hline & \multicolumn{2}{|c|}{$\begin{array}{l}\text { 9. Avaliação: Que estratégias serão implementadas para avaliar os processos e os produtos } \\
\text { dos alunos? }\end{array}$} \\
\hline & $\begin{array}{l}\text { Eu controlarei o conjunto das estratégias de } \\
\text { avaliação? }\end{array}$ & $\begin{array}{l}\text { Avaliação baseada em provas orais ou } \\
\text { escritas. }\end{array}$ \\
\hline & $\begin{array}{l}\text { O aluno poderá ser engajado ativamente } \\
\text { na avaliação de seu próprio processo de } \\
\text { aprendizagem? }\end{array}$ & $\begin{array}{l}\text { O dispositivo preverá tempo para } \\
\text { discussão, organizará a autoavaliação, os } \\
\text { alunos poderão escolher os critérios ou } \\
\text { meios de avaliação, }\end{array}$ \\
\hline \multirow{7}{*}{ 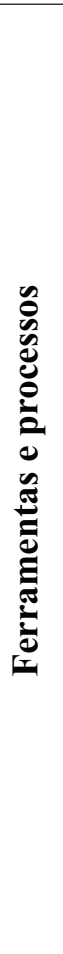 } & \multicolumn{2}{|c|}{ 10. Controle pelo aluno: Que tipo de participação será permitida ao aluno? } \\
\hline & $\begin{array}{l}\text { Os alunos poderão ter certo controle sobre o } \\
\text { dispositivo e seu processo de aprendizagem? }\end{array}$ & $\begin{array}{l}\text { O dispositivo e o ambiente permitirão aos } \\
\text { alunos participar de sua elaboração ou } \\
\text { avaliação. }\end{array}$ \\
\hline & \multicolumn{2}{|c|}{$\begin{array}{l}\text { 11. Gestão dos conhecimentos: Como os conhecimentos produzidos e aqueles trazidos pelos } \\
\text { professores serão geridos? }\end{array}$} \\
\hline & $\begin{array}{l}\text { Quero controlar eu mesmo os conteúdos que } \\
\text { os alunos deverão dominar? }\end{array}$ & $\begin{array}{l}\text { No dispositivo, o professor preverá a } \\
\text { maneira pela qual os conteúdos serão } \\
\text { agrupados e difundidos junto aos alunos. }\end{array}$ \\
\hline & $\begin{array}{l}\text { Considero o grupo uma comunidade de } \\
\text { aprendizagem que produz, compartilha e } \\
\text { reutiliza conhecimentos? }\end{array}$ & $\begin{array}{l}\text { O dispositivo preverá modalidades de } \\
\text { produção, de troca e de reutilização das } \\
\text { outras áreas de conhecimento ligadas à } \\
\text { disciplina assim como as ferramentas de } \\
\text { apoio. }\end{array}$ \\
\hline & \multicolumn{2}{|l|}{ 12. Regulação e avaliação do dispositivo } \\
\hline & $\begin{array}{l}\text { Conto com a mudança de certos elementos } \\
\text { no decorrer da disciplina? A visão/reação dos } \\
\text { alunos pode contribuir para melhorar meu } \\
\text { dispositivo? }\end{array}$ & $\begin{array}{l}\text { O professor antecipará as mudanças } \\
\text { que podem ocorrer no desenvolvimento } \\
\text { do dispositivo (papéis, funções). Uma } \\
\text { avaliação com os alunos poderá ser } \\
\text { realizada. }\end{array}$ \\
\hline
\end{tabular}




\section{CONSIDERAÇÕES FINAIS}

Certo número de problemas decorre da perspectiva de abordagem adotada nesta pesquisa. Uma das questões que se colocam diz respeito aos efeitos sobre o ensino e a aprendizagem dos recentes paradigmas de pesquisa em psicologia da educação (socioconstrutivismo, teoria da atividade, cognição distribuída, dentre outros) que influenciaram a concepção das plataformas (AVA) atuais. Avaliar os efeitos desses dispositivos seria comparar um processo de ensino e de aprendizagem a distância a um outro, presencial. Mas, essa comparação só faz sentido quando se observa que se afirmam as experiências de ensino híbridas e esses dois tipos de ensino possuem cada vez mais pontos em comum. Ou seja, o ensino mediado pelas TIC e pelos AVA alterna cada vez mais momentos de ensino a distância e presenciais.

Concretamente, quais seriam os modos de análise mais pertinentes e perseguindo quais objetivos? A autonomia, cada vez mais considerada uma responsabilidade do aluno, não tornaria complexa a avaliação dos referidos efeitos? Quais os métodos (experimentação controlada, análise dos usos) a serem seguidos, quais as variáveis (atitudes, habilidades e competências, modalidades comunicacionais) a serem utilizadas para adequar os dispositivos a seus objetivos pedagógicos?

Enfim, o processo de acompanhamento da implantação de projetos inovadores com a utilização de AVA indica a necessidade de um aprofundamento de diversas questões, tanto no que diz respeito à apropriação por parte dos professores, como por parte dos alunos. O Roteiro aqui apresentado pretende ser objeto de avaliação e de análise, provocando o tratamento de tais questões.

\section{ABSTRACT}

This article is based on the research project: 'Pedagogical support and evaluation of a non presence formation device: the use of technologies in virtual environments as a possibility for pedagogical innovation'. This research was carried out between 2007 and 2008 among teachers using the Moodle virtual learning environment to offer semi-presence-based subjects in undergraduate courses at the Catholic University of Goiás. Starting from the presupposition that ways of using ICTs could uncover new pedagogical practices and make innovative action possible, an action-research was undertaken whose final objective was to propose 'a Guidebook of support and evaluation of formation devices mediated by virtual learning environments (VLE)'. 
Keywords: Socio-technical approach. Virtual learning environment (VLE). Pedagogical device. Pedagogical innovation.

\section{NOTAS}

1. O conceito dispositivo de formação ou dispositivo pedagógico diz respeito ao "conjunto de atores (aprendizes, tutores, responsáveis pela formação) e de ferramentas técnicas organizadas no espaço e no tempo, de acordo com uma meta de aprendizagem" (Регхото, 2008, p.43). Ele pretende abordar as práticas e processos que envolvem a integração das TIC à educação, na perspectiva sociotécnica.

2. Na verdade, observa-se uma tendência à implantação de modelos híbridos no que diz respeito aos cursos a distância. Tal modelo refere-se à alternância entre atividades de ensino e de estudo realizadas à distância (com a utilização das TIC) e presencialmente.

3. Por efeito de retorno, a educação presencial poderia também se beneficiar dessa revisão metodológica.

\section{REFERÊNCIAS}

ARAÚJO, C. H. S. Discursos pedagógicos sobre os usos do computador na educação escolar (1997-2007). 2008. 178 p. Dissertação (Mestrado em Educação) -Universidade Católica de Goiás, 2008.

BARRETO, R. G. Tecnologias na formação de professores: o discurso do MEC. Educação e Pesquisa., São Paulo, v. 29, n. 2, p. 271-286, 2003.

BARRETO, R. G. et al. As tecnologias da informação e da comunicação na formação de professores. Rev. Bras. Educ., Rio de Janeiro, v. 11, n. 31, p. 31-42, 2006.

BARRETO, R. G.; LEHER, R. Do discurso e das condicionalidades do Banco Mundial, a educação superior "emerge" terciária. Rev. Bras. Educ. v.13, n.39, p. 423-436, 2008.

BELLONI, M. L. Ensaio sobre a educação a distância no Brasil. Educ. Soc., v. 23, n. 78, p. 117-142, 2002.

. Integração das Tecnologias de Informação e Comunicação aos Processos Educacionais. In: BARRETO, R. G. (Org.). Tecnologias Educacionais e Educação a distância. Rio de Janeiro: Quartet Editora, 2001. 
BERROUK, S.; JAILLET, A. Les TIC dans un contexte de formation à distance: une stratégie de redynamisation de formation en présentiel. Revue Internationale des Technologies en Pédagogie Universitaire. vol. 2, n. 2, p. 7-21, 2005.

BONNETON, D. L'innovation comme alternative à la formation? Dialogue, n. 96/97, p. 80-84, 1999.

CARVALHO, R. M. A.; MARTELLI, I. Reflexões sobre a utilização de metodologia não presencial em cursos de formação de professores. In: CIQEAD 2005. Congresso Internacional de Qualidade em EAD: desafios para a transformação social. 2005, São Leopoldo. Disponível em: <http://www.ricesu.com.br/ciqead2005/trabalhos/35.pdf $>$. Acesso em: 30 out. 2006.

CHARLIER B.; PERAYA D. (Ed.). Nouveaux dispositifs de formation pour l'enseignement supérieur: allier technologie et innovation. Bruxelles: De Boeck, 2002.

KENSKI, V. M. Gestão e uso das mídias em projetos de educação a distância. Revista E-Curriculum, v. 1, n. 1, dez./jul. 2005-2006. Disponível em: <http:// www.pucsp.br/ecurriculum>. Acesso em: 10 abr. 2009.

MARCHAND, L.; LOISIER, J. Pratiques d'apprentissage en ligne. Québec: Chenelière Éducation, 2005.

MORAN, J. M. A educação a distância e os modelos educacionais na formação de professores. In: BONIN, I. et al. Trajetórias e processos de ensinar e de aprender: políticas e tecnologias. Porto Alegre: EDIPUCRS, 2008.

. A Educação que desejamos: Novos desafios e como chegar lá. 2 ed. Campinas: Papirus, 2007.

. Contribuições para uma pedagogia da educação a distância no ensino superior. Interface, v. 7, n. 12, p. 147-147, 2003.

OLIVEIRA, M. R. N. S. Do mito da tecnologia ao paradigma tecnológico; a mediação tecnológica nas práticas didático-pedagógicas. Rev. Bras. Educ., n. 18, p. 101-107, 2001.

PEIXOTO, J. A inovação pedagógica como meta dos dispositivos de formação a distância. EccoS. v. 10, n. 1, p. 39-54, 2008.

. Metáforas e imagens dos formadores de professores na área da informática aplicada à educação. Educação e Sociedade, v. 28, n. 101, p. 1479-1500, 2007.

PETERS, O. A educação a distância em transição. Trad. Leila F. de S. Mendes. São Leopoldo: Unisinos, 2004.

. Didática do ensino a distância. Trad. Ilson Kayser. São Leopoldo: Unisinos, 2001. 
PRETTO, N. L. Educação, comunicação e a Anped: uma história em movimento. $30^{a}$ Reunião Anual de Pós-Graduação e Pesquisa em Educação (Anped). 2007, Caxambu. In: Anais...Caxambu, 2007.

. Políticas públicas educacionais: dos materiais didáticos aos multimedias. Revista de Educação, v. X, n. 1, 2001. Disponível em: <http://www2.ufba. $\mathrm{br} / \sim$ pretto/textos/revista\%20educacao $\% 20$ portugal/revksta $\% 20 \mathrm{de} \% 20$ educac ao\%20portugal.pdf $>$. Acesso em: 05 maio 2009.

. Educação e inovações tecnológicas: um olhar sobre as políticas públicas brasileiras. Rev. Bras. de Educ., n. 11, p. 75-85, 1999.

; PINTO, C. C. Tecnologias e novas educações. Rev. Bras. Educ., Rio de Janeiro, v. 11, n. 31, p. 19-30, 2006.

PROULX, S. Les différentes problématiques de l'usage et de l'usager. In: VITALIS, A. (sous la direction de). Médias et nouvelles technologies: Pour une socio-politique des usages. Rennes: Apogée, 1994, p.149-159.

SANTOS, E. O. dos. Educação on-line: a dinâmica sociotécnica para além da educação a distância. In: PRETTO, N. De L. (Org.). Tecnologia \& novas educações. Salvador: EDUFBA, 2005.

SIMONDON, G. Du mode d'existence des objets techniques. Paris: Aubier, 1989.

VALENTE, J. A.; ALMEIDA, M. E B. (org). Formação de educadores a distância e integração de mídias. São Paulo: Avercamp, 2007.

; PRADO, M. E. B. B.; ALMEIDA, M. E B. (org). Educação a distância via internet. São Paulo: Avercamp, 2003.

VEDEL, T. Introduction à une socio-politique des usages. In: VITALIS, A. (org.). Médias et nouvelles technologies de communication. Pour une socio-politique des usages. Rennes: Apogée, 1994, p.13-34.

VILLIOT-LECLERCQ, E. Genèse, réception, orientation et explicitation des scénarios pédagogiques. Vers un modèle de conception des scénarios par contraintes. Distances et savoirs, v. 5, n. 4, p. 507-526, 2007.

VITALIS, A. La part de citoyenneté dans les usages. In : (org.) Médias et nouvelles technologies. Pour une socio-politique des usages. Rennes: Apogée, 1994, p.35-43. 